\title{
BMJ Open Willingness to seek medical care for tuberculosis and associated factors among the elderly population in Shenzhen: a cross-sectional study
}

\author{
Yunxia Wang, ${ }^{1}$ Jing Feng, ${ }^{2}$ Juanjuan Zhang, ${ }^{1}$ Xin Shen, ${ }^{2}$ Zihui Lei, ${ }^{2}$ Yi Zhu, ${ }^{2}$ \\ Xin Meng, ${ }^{2}$ Hongkun Di, ${ }^{2}$ Wenqi Xia, ${ }^{2}$ Zuxun Lu, ${ }^{2}$ Yanfang Guo, ${ }^{1}$ Qing Yuan, ${ }^{1}$ \\ Xiaojun Wang, ${ }^{3}$ Yong Gan (1) ${ }^{2}$
}

To cite: Wang Y, Feng J, Zhang J, et al. Willingness to seek medical care for tuberculosis and associated factors among the elderly population in Shenzhen: a crosssectional study. BMJ Open 2021;11:e051291. doi:10.1136/ bmjopen-2021-051291

- Prepublication history and additional supplemental material for this paper are available online. To view these files, please visit the journal online (http://dx.doi.org/10.1136/ bmjopen-2021-051291).

YW and JF contributed equally.

Received 17 April 2021 Accepted 06 September 2021

Check for updates

(c) Author(s) (or their employer(s)) 2021. Re-use permitted under CC BY-NC. No commercial re-use. See rights and permissions. Published by BMJ.

For numbered affiliations see end of article.

\section{Correspondence to}

Yong Gan;

scswj2008@163.com and

Xiaojun Wang;

wangxiaojun_cn@163.com

\section{ABSTRACT}

Objectives This study was aimed to assess the willingness of elderly people to seek medical care for tuberculosis (TB) and the associated influencing factors. Design A cross-sectional study.

Setting A multistage random survey was conducted in Bao'an District of Shenzhen in China.

Participants A total of 1200 elderly people aged 65 or above were recruited for the study and completed a structured questionnaire between September and October 2019.

Main outcome measures Descriptive and binary logistic stepwise regression analyses were conducted to analyse the characteristics of elderly individuals, their willingness to seek medical care for TB and associated factors.

Results Among the final 1123 respondents, 943 (84.0\%) were willing to seek medical care if they discovered suspicious TB symptoms. Binary logistic stepwise regression analysis indicated that respondents whose family annual income per capita was 50000-100000¥ $(\mathrm{OR}=2.56,95 \% \mathrm{Cl}: 1.44$ to $4.54, \mathrm{p}<0.01)$ and who had positive attitudes ( $\geq 3$ scores: $0 \mathrm{R}=3.10,95 \% \mathrm{Cl}: 1.90$ to $5.05, p<0.01$ ) or practices ( $\geq 4$ scores: $O R=3.13,95 \% \mathrm{Cl}$ : 1.82 to $5.39, p<0.01$ ) towards TB were more willing to seek medical care for TB.

Conclusions Willingness to seek medical care for TB in the elderly population can be improved according to the determinants.

\section{INTRODUCTION}

Tuberculosis (TB) is a major cause of ill health, one of the top 10 causes of death worldwide, and the leading cause of death from a single infectious agent. In 2019, an estimated 10 million people worldwide fell ill with $\mathrm{TB}$, and 1.4 million died. ${ }^{1}$ The risk of TB increases with age, and the pace of population ageing is increasing in modern China. WHO has estimated that there will be 402 million people aged 60 or above in China by $2040 .^{2}$ The Fifth National TB Epidemiological Survey revealed that $48.8 \%$ of TB patients were over 60 years old, while the prevalence
Strengths and limitations of this study

- This is the first study to investigate willingness to seek medical care for tuberculosis (TB) among elderly individuals in China.

- The logistic regression model provides quantified results of the influencing factors of willingness to seek medical care for TB among elderly individuals, which could provide a reference for TB control policies.

- There may be more potential influencing factors of willingness to seek medical care for TB than those we investigated in the study.

- The cross-sectional study design is limited in terms of identifying the causality of the observed relationships.

of active TB in the elderly population over 65 years old was determined to be $1270 / 100000 .{ }^{3}$ According to the Chinese Centre for Disease Control and Prevention, a total of 775764 cases of TB were reported in the National Notifiable Disease Reporting System in 2019. ${ }^{4}$ The reporting rate of TB cases increased with age, with $197730(25.5 \%)$ cases among people aged 65 or older. ${ }^{4}$ Elderly people are one of the bottlenecks in TB control in China, and more TB preventive measures are urgently needed to reach the most vulnerable populations.

Currently, the 'trinity' model of TB prevention and treatment in China comprises the Centre for Disease Control and Prevention, designated $\mathrm{TB}$ diagnostic and treatment hospitals and primary healthcare institutions. ${ }^{5}$ This model plays an important role in $\mathrm{TB}$ control and has made some progress. However, the rate of delay in TB diagnosis and treatment has remained high among the elderly, ${ }^{6-8}$ which is a major contributor to poor outcomes and TB transmission. The willingness to seek medical care of elderly 
people with possible symptoms could predict the actual behaviour of seeking care in TB prevention and treatment institutions. In addition, positive behaviour related to TB could both improve the detection rate for the disease and also reduce the proportion of delayed diagnosis and treatment. ${ }^{9}$ Therefore, this study aimed to examine willingness to seek medical care for TB and its determinants among elderly people aged 65 or older. The findings may provide references for TB prevention and control among the elderly.

\section{METHODS}

\section{Study setting}

Shenzhen, a highly developed region in China, had an estimated population of more than 13.4 million in 2019. ${ }^{10}$ The percentage of the migrant population was $63.2 \%$ in Shenzhen compared with $80.5 \%$ in Bao'an District. ${ }^{10}$ The immigrants were mostly poor, had a low level of education and lived in circumstances conducive to TB transmission. ${ }^{11}{ }^{12}$ Although the incidence of TB has declined in Shenzhen, the prevalence of TB has remained high in Bao'an District due to a high TB case load caused by a heavy concentration of migrants.

The Chinese government launched the directly observed treatment +short (DOTS) course chemotherapy strategy to control the TB epidemic in 1990 and has followed this protocol since then. ${ }^{13}$ Shenzhen was one of the first cities in China to implement the DOTS strategy in 1993, and its coverage at the individual level reached $100 \%$ in $2000 .{ }^{14}$ Economy and social progress developed rapidly in Shenzhen, which was the first established special economic zone in China. The region has a robust healthcare infrastructure, providers, service culture and conditions for timely diagnosis and treatment. ${ }^{9}{ }^{12}$ The Centre for Chronic Disease Control, the local institution designated for TB management, provides TB diagnosis, treatment and management. Patients have free access to anti-TB fix-dose combination products and must undergo standard anti-TB treatment. ${ }^{15}$ After patients start to take anti-TB drugs, they are required to visit the Centre for Chronic Disease Control every month for health checks until the treatment ends. ${ }^{11}$ In addition to free TB drugs, the government provides subsidies for transportation and nutrition for low-income TB patients. ${ }^{16}$ However, all patients must pay for monthly prescriptions for subsidiary drugs such as liver protection drugs, and auxiliary examinations, such as X-ray tests. ${ }^{11} 17$

\section{Study population and sampling}

This study was conducted between September and October 2019 in Bao'an District of Shenzhen. With a confidence interval (CI) of 95\%, an estimated proportion of $92.2 \%^{18}$ and an absolute error of $5 \%$, the sample size was rounded to 113 according to the formula, $\mathrm{n}=$ $\left[Z^{2} p(1-p)\right] / d^{2}$. To compensate for non-responses, the sample size was increased by $10 \%$ to 124 .
A multistage random sampling method was performed in the study. First, two of eight community health service centres with chest X-ray film screening capabilities in Bao'an District were selected randomly. Second, 600 people aged 65 or above who received health examinations were randomly selected from every community health service centre. Elderly people in the study communities were included in the survey if they: (1) were aged 65 or older, (2) had resided in the area for at least half a year, (3) had no communication disorders or mental illnesses and (4) were willing to complete the survey. Respondents were excluded if they did not meet any of the above requirements.

\section{Patient and public involvement}

No patients were involved in this study.

\section{Study design and instrument}

A cross-sectional study was used to collect data from the elderly population through face-to-face interviews with a structured questionnaire. Based on the actual conditions of elderly people in Shenzhen and the context of healthcare in China, we designed a questionnaire according to previous literature. ${ }^{18-21}$ The questionnaire contained four sections: (1) demographic characteristics, such as gender, age, residence, duration of residence in Shenzhen, education level, marital status, medical insurance and family annual income per capita; (2) health-related characteristics, including self-perceived health status, smoking and alcohol consumption habits and previous history of TB; (3) knowledge, attitudes and practices (KAP) for TB prevention and control; ${ }^{22}$ and (4) willingness to seek medical care for $\mathrm{TB}$ and specific reasons for being unwilling to seek medical care for TB (online supplemental appendix). In the TB KAP section, incorrect, inappropriate or uncertain (do not know) responses received a 0 score, while 1 point was assigned if the respondent chose the correct or appropriate answer; correctness or appropriateness was based on current literature and best practices. The respondents who answered $60 \%$ of the KAP questions correctly or appropriately were considered aware of $\mathrm{TB}$ or to have positive attitudes or practices regarding $\mathrm{TB}$.

\section{Data collection and quality control}

The questionnaire was designed based on literature review, group discussions and mock interviews. A pilot study of 40 elderly people was conducted at one of the community health service centres in the Bao'an District of Shenzhen to improve the quality of the questionnaire. A total of 38 of those respondents were able to clearly understand all the questions of the questionnaire, and further modifications were made according to their feedback. The questionnaire had good validity among elderly people. The data were collected by trained investigators through a field questionnaire survey. A logic check of all data was undertaken to determine whether there were any contradictions. Logical errors were identified 
as certain mismatched sociodemographic characteristics; for example, an individual aged 70 years old reported a duration of residence in Shenzhen of more than 70 years.

\section{Statistical analysis}

All statistical procedures were performed using SPSS V.22.0 software. The descriptive statistics are presented as the number of observations in percentages $(\%) \cdot \chi^{2}$ tests were conducted to compare the willingness of the elderly to seek medical care for TB between groups. A binary stepwise logistic regression model was used to analyse the factors associated with willingness to seek medical care for TB among the elderly (levels for selection and elimination $\mathrm{p}=0.05$ and $\mathrm{p}=0.10$, respectively), including a neutral attitude or unwillingness as the reference category. In the binary model, independent variables were age (65-70, 71-75, >75), gender (male, female), residence (local residents, others), education (primary school or below, junior or senior middle school, college degree or above), marital status (married, unmarried/widowed/divorced), medical insurance (yes, no), family annual income per capita (<50000¥, 50 000-100000¥, 100 000-200000¥, $>200000 ¥$ ), self-perceived health status (good, fair, bad), smoking status (current smoker, former smoker, never smoked), alcohol intake (current drinker, former drinker, never drank), TB knowledge scores $(<3, \geq 3)$, TB attitudes $(<3, \geq 3)$ and TB practices $(<4, \geq 4)$. The odds ratio (OR) and $95 \%$ CI for each variable were calculated. All tests were two-sided with a significance level of 0.05 .

\section{RESULTS}

Initially, 1200 elderly people were recruited for the survey, of whom $11(0.92 \%)$ refused to participate. Based on the inclusion and exclusion criteria, 1172 participants were ultimately included in the analyses. Because a previous history of TB might have influenced willingness to seek medical care for $\mathrm{TB}$, we further excluded 35 participants who had previously been treated for TB. Then, we deleted eight questionnaires due to missing data on willingness to seek medical care for TB. Additionally, we discarded six questionnaires with logical errors. Finally, 1123 eligible questionnaires remained for analysis.

The characteristics of the participants are reported in table 1. Among 1123 participants (response rate, $94.45 \%$ ), $505(45.3 \%)$ were males and $584(52.5 \%)$ were aged $65-70$ years. More than half $(55.4 \%)$ had an educational level of primary school or below. The majority $(78.8 \%)$ held nonShenzhen household registrations, and $947(89.0 \%)$ were married. Most $(73.3 \%)$ of the participants had medical insurance. Of the respondents, $398(37.8 \%)$ had a family annual income per capita lower than 50 000¥. Less than half $(48.1 \%)$ reported having a good self-perceived health status. Only $119(10.7 \%)$ and $106(9.5 \%)$ were current cigarette smokers and alcohol drinkers, respectively. The knowledge awareness rate for TB among them was $69.1 \%$. The
Table 1 Characteristics of the study population*

\begin{tabular}{lll}
\hline Variables & N & $\%$ \\
\hline Total & 1123 & 100
\end{tabular}

Age, years

\begin{tabular}{lrr}
\hline $65-70$ & 584 & 52.5 \\
\hline $71-75$ & 312 & 28.0 \\
\hline 75 & 217 & 19.5 \\
\hline Gender & & \\
\hline Male & 505 & 45.3 \\
\hline Female & 611 & 54.7 \\
\hline Residence & & \\
\hline Local residents & 232 & 21.2 \\
\hline Others & 862 & 78.8 \\
\hline Education level & & \\
\hline Primary school or below & 605 & 55.4 \\
\hline Junior or senior middle school & 423 & 38.7 \\
\hline College degree or above & 64 & 5.9 \\
\hline Marital status & & \\
\hline Married & 947 & 89.0 \\
\hline Unmarried/widow/divorced & 117 & 11.0 \\
\hline Medical insurance & & \\
\hline Yes & 779 & 73.3 \\
\hline No & 284 & 26.7 \\
\hline Family annual income per capita & & \\
\hline
\end{tabular}

Family annual income per capita ( $¥)$

\begin{tabular}{|c|c|c|}
\hline$<50000$ & 398 & 37.8 \\
\hline $50000-100000$ & 342 & 32.4 \\
\hline $100000-200000$ & 221 & 21.0 \\
\hline$>200000$ & 93 & 8.8 \\
\hline \multicolumn{3}{|c|}{ Self-perceived health status } \\
\hline Good & 505 & 48.1 \\
\hline Fair & 476 & 45.3 \\
\hline Bad & 69 & 6.6 \\
\hline \multicolumn{3}{|l|}{ Smoking status } \\
\hline Current smoker & 119 & 10.7 \\
\hline Former smoker & 92 & 8.3 \\
\hline Never smoker & 902 & 81.0 \\
\hline \multicolumn{3}{|l|}{ Alcohol intake } \\
\hline Current drinker & 106 & 9.5 \\
\hline Former drinker & 82 & 7.3 \\
\hline Never drinker & 931 & 83.2 \\
\hline \multicolumn{3}{|l|}{ TB knowledge scores } \\
\hline$<3$ & 333 & 30.9 \\
\hline$\geq 3$ & 746 & 69.1 \\
\hline
\end{tabular}

TB attitudes scores

$\begin{array}{ccc}<3 & 546 & 52.0 \\ \geq 3 & 505 & 48.0 \\ \text { TB practice scores } & & \end{array}$

Continued 


\begin{tabular}{ccc}
\hline Table 1 Continued & & \\
\hline Variables & N & $\%$ \\
\hline$<4$ & 555 & 57.8 \\
$\geq 4$ & 406 & 42.2
\end{tabular}

${ }^{*}$ Missing number of participants: age: 10; gender: 7; residence: 29; education level: 31; marital status: 59 ; medical insurance: 60; family annual income per capita: 69 ; self-perceived health status: 73 ; smoking status: 10 ; alcohol consumption habits: 4 ; TB knowledge scores: 44; TB attitudes scores: 72; TB practice scores: 162.

TB, tuberculosis.

percentages of respondents who had positive attitudes or practices were $48.0 \%$ and $42.2 \%$, respectively.

A total of $943(84.0 \%)$ respondents would choose to seek medical care if they exhibited possible TB symptoms, whereas $155(13.8 \%)$ were unwilling to seek treatment. Additionally, when we investigated the reasons for unwillingness to seek medical care for TB, $82(52.9 \%)$ reported 'long treatment cycle and heavy financial burden' as the main reason (table 2 ).

Table 3 demonstrates the results of a comparison of willingness to seek medical care for $\mathrm{TB}$ among various groups. There were significant differences in willingness to seek medical care for TB across scores for TB KAP $(p<0.05)$. There were no significant differences in willingness to seek medical care for TB across genders, ages, residences, education levels, marital statuses, medical insurance statuses, family annual income per capita levels, self-perceived health statuses, tobacco use, or alcohol consumption $(\mathrm{p}>0.05)$.

Table 4 shows the results of the binary logistic regression analysis to determine factors associated with willingness to seek medical care for TB among the elderly. Family annual income per capita (50 000-100000¥: $\mathrm{OR}=2.56,95 \%$ CI: 1.44 to 4.54$)$, attitudes towards TB ( $\geq 3$ : OR=3.10,95\% CI: 1.90 to 5.05$)$ and practices towards TB ( $\geq 4:$ OR=3.13, 95\% CI: 1.82 to 5.39 ) were significant predictors of the respondents' willingness to seek medical care for TB.

\section{DISCUSSION}

This was the first study to investigate the willingness of elderly individuals to seek medical care for TB in China.
We found that $84.0 \%$ of the participants were willing to seek medical care for TB, while $13.8 \%$ were unwilling to seek medical care for TB. Individuals with possible TB symptoms who do not seek medical care will miss the opportunity for early detection of TB, leading to delayed treatment and poor prognoses. ${ }^{23-25}$ In addition, unwillingness to seek medical care may increase the potential risk of transmission and will have a negative impact on their families and society. ${ }^{26}$

Our findings showed that the main reason for being unwilling to seek medical care for TB was 'long treatment cycle and heavy economic burden'. This indicated that individuals' economic situation impacts their willingness to seek treatment. In China, the policy that TB diagnosis and anti-TB drugs are free is not well understood, and some even doubt its authenticity. ${ }^{28}$ In addition, the free items provided by the government accounted for less than $40 \%$ of the total cost of TB diagnosis and treatment, meaning that TB patients still must pay more than half of the total cost. ${ }^{29}$ This may explain the effects of economic situation on willingness to seek medical care for TB. Similarly, the economic burden has been found to be a key factor hindering health-seeking behaviours among TB patients, as well as a primary concern for TB control in India, ${ }^{23}$ Indonesia, ${ }^{30}$ Malawi, ${ }^{31}$ the Middle East and North Africa. ${ }^{32}$ To reduce the economic burden on TB patients, it is important for the government to expand health insurance coverage and lower the costs of TB treatment. The economic factor was further supported by the multivariate analysis result that family annual income per capita affected the willingness of the elderly to seek treatment. However, the significant association between family annual income per capita and willingness to seek medical care appeared only in the respondents who had $50000-100000 ¥$ of family annual income per capita. The percentage of respondents whose family annual income per capita was more than $100000 ¥$ was relatively low in our study. Income is a sensitive topic and elderly people may under-report it. Thus, the effects of high family annual income per capita on willingness to seek medical care may have been underestimated in this study.

Many participants worried about being discriminated against for visiting TB prevention and treatment institutions, which was another important factor hindering their willingness to seek treatment. This was consistent with previous findings in South Africa, ${ }^{33}$ Ethiopia, ${ }^{34}$

Table 2 Distribution according to the reasons of unwillingness to seek medical care for TB among elderly population $(n=155)$

\begin{tabular}{lrr}
\hline Items & $\mathbf{N}$ & $\%$ \\
\hline Lack of trust in the medical level of TB prevention and treatment institutions & 40 & 25.8 \\
Poor attitude of medical staff & 8.2 \\
Long treatment time and heavy economic burden & 82 & 52.9 \\
Fear of discrimination & 46 & 29.7 \\
Others & 55 & 35.5 \\
\hline
\end{tabular}

TB, tuberculosis. 
Table 3 Factors associated with medical care-seeking willingness for tuberculosis among elderly population* $(n=1123)$

\begin{tabular}{|c|c|c|c|c|c|}
\hline Variables & Willing & Neutral & Unwilling & $\chi^{2}$ & $\begin{array}{l}P \\
\text { value }\end{array}$ \\
\hline Total & $943(84.0)$ & $25(2.2)$ & $155(13.8)$ & & \\
\hline \multicolumn{6}{|l|}{ Age, years } \\
\hline $65-70$ & $490(52.4)$ & $12(48.0)$ & $82(53.9)$ & 1.74 & 0.78 \\
\hline $71-75$ & $262(28.0)$ & $6(24.0)$ & $44(28.9)$ & & \\
\hline$>75$ & $184(19.7)$ & $7(28.0)$ & $26(17.1)$ & & \\
\hline \multicolumn{6}{|l|}{ Gender } \\
\hline Male & $430(45.9)$ & $12(48.0)$ & $63(40.6)$ & 1.58 & 0.45 \\
\hline Female & $506(54.1)$ & $13(52.0)$ & $92(59.4)$ & & \\
\hline \multicolumn{6}{|l|}{ Residence } \\
\hline Local residents & $185(20.2)$ & 9 (36.0) & $38(24.8)$ & 5.04 & 0.08 \\
\hline Others & $731(79.8)$ & $16(64.0)$ & $115(75.2)$ & & \\
\hline \multicolumn{6}{|l|}{ Education level } \\
\hline Primary school or below & $503(54.9)$ & $13(54.2)$ & $89(58.9)$ & 3.23 & 0.52 \\
\hline Junior or senior middle school & 363 (39.6) & $10(41.7)$ & $50(33.1)$ & & \\
\hline College degree or above & $51(5.6)$ & $1(4.2)$ & $12(7.9)$ & & \\
\hline \multicolumn{6}{|l|}{ Marital status } \\
\hline Married & $795(89.1)$ & $22(91.7)$ & $130(87.8)$ & 0.39 & 0.82 \\
\hline Unmarried/widow/divorced & $97(10.9)$ & $2(8.3)$ & $18(12.2)$ & & \\
\hline \multicolumn{6}{|l|}{ Medical insurance } \\
\hline Yes & $657(73.7)$ & 19 (79.2) & $103(69.6)$ & 1.55 & 0.46 \\
\hline No & $234(26.3)$ & $5(20.8)$ & $45(30.4)$ & & \\
\hline \multicolumn{6}{|l|}{ Family annual income per capita ( $¥)$} \\
\hline$<50000$ & $337(38.0)$ & $9(39.1)$ & $52(36.1)$ & 9.39 & 0.15 \\
\hline $50000-100000$ & $300(33.8)$ & $5(21.7)$ & $37(25.7)$ & & \\
\hline $100000-200000$ & $173(19.5)$ & $7(30.4)$ & $41(28.5)$ & & \\
\hline$>200000$ & $77(8.7)$ & $2(8.7)$ & $14(9.7)$ & & \\
\hline \multicolumn{6}{|l|}{ Self-perceived health status } \\
\hline Good & $420(47.8)$ & $11(50.0)$ & $74(49.7)$ & 1.16 & 0.89 \\
\hline Fair & $403(45.8)$ & $10(45.5)$ & $63(42.3)$ & & \\
\hline Bad & $56(6.4)$ & $1(4.5)$ & $12(8.1)$ & & \\
\hline \multicolumn{6}{|l|}{ Smoking status } \\
\hline Current smoker & $105(11.3)$ & $3(12.0)$ & $11(7.1)$ & 4.73 & 0.32 \\
\hline Former smoker & $78(8.4)$ & $0(0.0)$ & $14(9.0)$ & & \\
\hline Never smoker & $750(80.4)$ & $22(88.0)$ & $130(83.9)$ & & \\
\hline \multicolumn{6}{|l|}{ Alcohol intake } \\
\hline Current drinker & $91(9.7)$ & $4(16.0)$ & $11(7.1)$ & 2.39 & 0.67 \\
\hline Former drinker & $68(7.2)$ & $2(8.0)$ & $12(7.7)$ & & \\
\hline Never drinker & $780(83.1)$ & $19(76.0)$ & $132(85.2)$ & & \\
\hline \multicolumn{6}{|l|}{ TB knowledge scores } \\
\hline$<3$ & $249(27.5)$ & $12(50.0)$ & $72(48.3)$ & 30.25 & $<0.01$ \\
\hline$\geq 3$ & 657 (72.5) & $12(50.0)$ & $77(51.7)$ & & \\
\hline \multicolumn{6}{|l|}{ TB attitudes scores } \\
\hline$<3$ & 417 (47.3) & $15(65.2)$ & $114(77.6)$ & 47.74 & $<0.01$ \\
\hline$\geq 3$ & $464(52.7)$ & 8 (34.8) & $33(22.4)$ & & \\
\hline
\end{tabular}


Table 3 Continued

\begin{tabular}{llrrr}
\hline Variables & Willing & Neutral & Unwilling & $\chi^{2}$ \\
\hline TB practice scores & & & & \\
\\
$<4$ & $433(53.6)$ & $18(85.7)$ & $104(78.8)$ & 36.41 \\
$\geq 4$ & $375(46.4)$ & $3(14.3)$ & $28(21.2)$ & $<0.01$ \\
\hline
\end{tabular}

*Missing number of participants: age: 10; gender: 7; residence: 29; education level: 31; marital status: 59; medical insurance: 60; family annual income per capita: 69; self-perceived health status: 73; smoking status: 10; alcohol consumption habits: 4; TB knowledge scores: 44; TB attitudes scores: 72; TB practice scores: 162.

TB, tuberculosis.

India, Bangladesh, Malawi and Columbia. ${ }^{35}$ Previous studies have shown that TB patients suffer from widespread discriminatory and differential treatment due to long-term stereotypes about TB. ${ }^{33} 36$ The fear of being discriminated against can affect elderly people' willingness to seek medical care, health-seeking behaviours and compliance during the treatment process. ${ }^{93} 37$ In addition, evidence has shown that TB stigma was associated with patient delay and diagnostic delay. ${ }^{9}$ Available evidence suggests that measures aimed at empowering TB patients to resist stigmatising perceptions, as well as efforts to change norms related to TB, can be effective in reducing the stigma associated with $\mathrm{TB} .{ }^{38}$ To increase the willingness of the elderly population to seek medical care and enable them to receive timely treatment, it is crucial to further popularise knowledge about $\mathrm{TB}$ and eliminate the denigration and stigmatisation of TB through a variety of effective educational methods.

The results of the multivariate analysis showed that higher scores on attitudes and behaviours related to TB prevention and control were associated with greater willingness to seek medical care for TB. However, the prevalence of positive attitudes and practices towards TB was low. Therefore, measures should be taken to improve TB-related attitudes and behaviours among the elderly, which may help to increase willingness to seek medical care for TB. Intriguingly, we found that TB knowledge scores were not a significant determinant of willingness to seek medical care in the multivariate analysis, which was not in line with previous studies. ${ }^{9} 25263239$ Therefore, the association between TB knowledge and willingness to seek medical care needs further research.

This study had several strengths. First, it was the first to investigate the willingness of the elderly to seek medical care for TB in China. Second, our research found that certain important factors were associated with willingness to seek medical care, which could provide a reference for TB control policies among elderly people. However, some limitations should be noted. First, there may be more potential influencing factors of willingness to seek medical care than those we investigated in the study. Second, we listed 'others' as an open-ended response to reasons for unwillingness to seek medical care for TB but failed to acquire information about the specific other reasons, as the respondents did not provide detailed answers to this question. In future research, we could consider designing specific responses to investigate elderly people's additional reasons for being unwilling to seek medical care for TB. Third, the study was cross-sectional, and thus was limited in terms of identifying the causality of the

Table 4 Binary logistic regression analysis for the association with medical care-seeking willingness for tuberculosis among elderly population* $(n=903)$

\begin{tabular}{|c|c|c|c|c|c|}
\hline Variables & B & SE & Wald $\chi^{2}$ & $P$ value & OR $(95 \% \mathrm{Cl})$ \\
\hline 50 000-100000 & 0.94 & 0.29 & 10.37 & $<0.01$ & $2.56(1.44$ to 4.54$)$ \\
\hline$>200000$ & 0.29 & 0.39 & 0.57 & 0.45 & $1.34(0.63$ to 2.86$)$ \\
\hline \multicolumn{6}{|c|}{ TB attitudes scores (ref: <3) } \\
\hline \multicolumn{6}{|c|}{ TB practice scores (ref: <4) } \\
\hline$\geq 4$ & 1.14 & 0.28 & 16.93 & $<0.01$ & $3.13(1.82$ to 5.39$)$ \\
\hline
\end{tabular}

${ }^{*}$ Adjustment for age $(65-70,71-75,>75)$, gender (male, female), residence (local residents, others), education (primary school or below, junior or senior middle school, college degree or above), marital status (married, unmarried/widow/divorced), medical insurance (yes, no), selfperceived health status (good, fair, bad), smoking status (current smoker, former smoker, never smoker), alcohol intake (current drinker, former drinker, never drinker), TB knowledge scores $(<3, \geq 3)$ and other variables in the model.

OR, odds ratio; SE, standard error; TB, tuberculosis. 
observed relationships. Fourth, this study enrolled only elderly people in Shenzhen, limiting the generalisability of the findings to other geographical regions.

\section{CONCLUSION}

In summary, this study found that family annual income per capita and TB-related attitudes and practices were significant predictors of willingness to seek medical care for TB among the elderly population. It is necessary to publicise TB-related knowledge and policies among the elderly. Measures must be taken to reduce the economic burden, clarify social misconceptions about TB and eliminate discrimination against $\mathrm{TB}$ patients.

\section{Author affiliations}

${ }^{1}$ Dapartment of Tuberculosis Prevention and Control, Shenzhen Bao'an Centre for Chronic Disease Control, Shenzhen, Guangdong, China

${ }^{2}$ Department of Social Medicine and Health Management, Huazhong University of Science and Technology Tongji Medical College, Wuhan, Hubei, China

${ }^{3}$ Office of Tuberculosis Control and Management, Wuhan Institute for Tuberculosis Control, Wuhan Pulmonary Hospital, Wuhan, Hubei, China

Correction notice This article has been corrected since it was published. Funding statement has been corrected.

Acknowledgements We thank the elderly population who participated in this research.

Contributors YW, JF and YoG conceived and designed the study. JF, JZ, XS, YZ, XM, $H D, Y a G, Q Y$ and $X W$ participated in the acquisition of data. YW and XS analysed the data. ZiL, ZuL, XW and YoG gave advice on methodology. YW and JF wrote the draft of the paper. All authors contributed to writing, reviewing or revising the paper and read and approved the final manuscript. YoG is the guarantor of this work and has full access to all the data in the study and takes responsibility for its integrity and the accuracy of the data analysis.

Funding This work was supported by A Major Infectious Disease Prevention and Control of the National Science and Technique Major Project (2018ZX10715004), Natural Science Foundation of Hubei Province (2020CFB218), Health Commission of Hubei Province Scientific Research Project (WJ2019H400), and Scientific Research Fund of Wuhan Municipal Health Commission (WG19Q03).

Competing interests None declared.

Patient consent for publication Not required.

Ethics approval The study was approved by the Ethics Committee of the Tongji Medical College Institutional Review Board, Huazhong University of Science and Technology, Wuhan, China. Informed consent was obtained from all survey participants.

Provenance and peer review Not commissioned; externally peer reviewed.

Data availability statement Data are available upon reasonable request. Data may be made available by contacting the corresponding author.

Supplemental material This content has been supplied by the author(s). It has not been vetted by BMJ Publishing Group Limited (BMJ) and may not have been peer-reviewed. Any opinions or recommendations discussed are solely those of the author(s) and are not endorsed by BMJ. BMJ disclaims all liability and responsibility arising from any reliance placed on the content. Where the content includes any translated material, BMJ does not warrant the accuracy and reliability of the translations (including but not limited to local regulations, clinical guidelines, terminology, drug names and drug dosages), and is not responsible for any error and/or omissions arising from translation and adaptation or otherwise.

Open access This is an open access article distributed in accordance with the Creative Commons Attribution Non Commercial (CC BY-NC 4.0) license, which permits others to distribute, remix, adapt, build upon this work non-commercially, and license their derivative works on different terms, provided the original work is properly cited, appropriate credit is given, any changes made indicated, and the use is non-commercial. See: http://creativecommons.org/licenses/by-nc/4.0/.
ORCID iD

Yong Gan http://orcid.org/0000-0002-7330-2937

\section{REFERENCES}

1 World Health Organization. Global tuberculosis report 2020. Geneva: World Health Organization, 2020. https://www.who.int/publications/i/ item/9789240013131

2 World Health Organization. China country assessment report on ageing and health. Geneva: World Health Organization, 2015. https:// www.who.int/ageing/publications/china-country-assessment/zh/

3 Wang Y. Data compilation of the fifth national tuberculosis epidemiological sampling survey in China. Beijing: Military Medical Science Press, 2011.

4 Chen W, Zhang H, Du X, et al. Characteristics and morbidity of the tuberculosis epidemic - China, 2019. China CDC Weekly 2020;2:181-4.

5 General Office of the State Council of the People's Republic of China. National tuberculosis prevention and control plan (2011-2015), 2020. Available: http://www.gov.cn/zhengce/content/2011-12/06/content_ 6143.htm

6 Li Y, Wang Z, Geng H. Current status and influencing factors of delayed visits to elderly pulmonary tuberculosis patients in Shandong Province. Chin J Gerontology 2013;33:1125-7.

7 Yang J, Du Y, Zhao Y. Patient delay and the impact factors for senile pulmonary tuberculosis in rural area. Chin Rural Health Serv Admin 2010;30:300-2.

8 Shen H, Du Y, Zhang G. Influencing factors of pulmonary tuberculosis patient delay in Guangzhou, 2008-2018. Chin J Antituberc 2020;42:510-7.

9 Li Y, Ehiri J, Tang S, et al. Factors associated with patient, and diagnostic delays in Chinese TB patients: a systematic review and meta-analysis. BMC Med 2013;11:156.

10 Shenzhen Bureau of Statistics, Shenzhen Investigation Team of National Bureau of Statistics. Shenzhen statistical Yearbook 2020. Beijing: China Statistics Press, 2020.

11 Huang Y, Huang J, Su X, et al. Analysis of the economic burden of diagnosis and treatment on patients with tuberculosis in Bao'an district of Shenzhen City, China. PLoS One 2020;15:e0237865.

$12 \mathrm{Xu} \mathrm{X,} \mathrm{Liu} \mathrm{J-H,} \mathrm{Cao} \mathrm{S-Y,} \mathrm{et} \mathrm{al.} \mathrm{Delays} \mathrm{in} \mathrm{care} \mathrm{seeking,} \mathrm{diagnosis} \mathrm{and}$ treatment among pulmonary tuberculosis patients in Shenzhen, China. int $j$ tuberc lung dis 2013;17:615-20.

13 China Tuberculosis Control Collaboration. The effect of tuberculosis control in China. The Lancet 2004;364:417-22.

14 Zhu L, Yang Y-Z, Guan H-Y, et al. Trends in drug-resistant tuberculosis after the implementation of the dots strategy in Shenzhen, China, 2000-2013. int j tuberc lung dis 2017;21:759-65.

15 Tang $\mathrm{Y}$, Zhao M, Wang Y, et al. Non-adherence to anti-tuberculosis treatment among internal migrants with pulmonary tuberculosis in Shenzhen, China: a cross-sectional study. BMC Public Health 2015; 15:474.

16 Lu H, Yan F, Wang W, et al. Do transportation subsidies and living allowances improve tuberculosis control outcomes among internal migrants in urban Shanghai, China? WPSAR 2013;4:19-24.

17 Liu Q, Smith H, Wang Y. Tuberculosis patient expenditure on drugs and tests in subsidised, public services in China: a descriptive study. Trop Med Int Health 2010;15:26-32.

18 Zhao M, Wang W, Tang Y. Survey on knowledge, attitude and practice about tuberculosis prevention and treatment among residents in Bao'an district of Shenzhen. J Clin Pulm Med 2015;20:1567-71.

19 National Health and Family Planning Commission of the People's Republic of China. Notice of the National Health and Family Planning Commission of the People's Republic of China on the issuance of the work plan for the dissemination of knowledge on tuberculosis prevention and control by millions of volunteers and the core information and knowledge points on tuberculosis prevention and control, 2021. Available: http://www.nhc.gov.cn/jkj/s3589/201604/ 2dd6a74584d34a6ba0dd863544e83416.shtml

$20 \mathrm{Ma}$ J. Study on the elderly pulmonary tuberculosis epidemic characteristic in Dongchuan district and awareness of tuberculosis prevention and control knowledge. Kunming: Kunming Medical University, 2015.

21 Lu C, Che X, Li M. Investigation on public awareness in key information of tuberculosis prevention and control in Shenzhen. $J$ Tuberc Lung Health 2019;8:259-64.

22 Wang Y, Gan Y, Zhang J, et al. Analysis of the current status and associated factors of tuberculosis knowledge, attitudes, and practices among elderly people in Shenzhen: a cross-sectional study. BMC Public Health 2021;21:1163. 
23 Thomas BE, Thiruvengadam K, S. R, et al. Understanding health care-seeking behaviour of the tribal population in India among those with presumptive TB symptoms. PLoS One 2021;16:e0250971.

24 Helfinstein S, Engl E, Thomas BE, et al. Understanding why at-risk population segments do not seek care for tuberculosis: a precision public health approach in South India. BMJ Glob Health 2020;5:e002555.

25 Tong Y, Guan X, Hou S, et al. Determinants of health Care-Seeking delay among tuberculosis patients in rural area of central China. Int $J$ Environ Res Public Health 2018;15:1998.

26 Obsa MS, Daga WB, Wosene NG, et al. Treatment seeking delay and associated factors among tuberculosis patients attending health facility in Ethiopia from 2000 to 2020: a systematic review and meta analysis. PLoS One 2021;16:e0253746.

27 Chen X, Wang W, Wang X, et al. Public awareness of tuberculosis in Southeast China: a population-based study. Int J Environ Res Public Health 2019;16:4290.

28 Wang J, Fei Y, Shen $\mathrm{H}$, et al. Gender difference in knowledge of tuberculosis and associated health-care seeking behaviors: a cross-sectional study in a rural area of China. BMC Public Health 2008;8:354

$29 \mathrm{Li} \mathrm{Y,} \mathrm{Li} \mathrm{X,} \mathrm{Xie} \mathrm{HB.} \mathrm{Analysis} \mathrm{on} \mathrm{the} \mathrm{reimbursement} \mathrm{situation} \mathrm{of} \mathrm{TB}$ treatment costs in the new rural cooperative medical system. Chin $J$ Antituberc 2010;32:685-9.

30 Rintiswati N, Mahendradhata Y, et al. Journeys to tuberculosis treatment: a qualitative study of patients, families and communities in Jogjakarta, Indonesia. BMC Public Health 2009;9:158.
31 Meghii J, Gregorius S, Madan J, et al. The long term effect of pulmonary tuberculosis on income and employment in a low income, urban setting. Thorax 2021;76:387-95.

32 Eltayeb D, Pietersen E, Engel M, et al. Factors associated with tuberculosis diagnosis and treatment delays in middle East and North Africa: a systematic review. East Mediterr Health $\mathrm{J}$ 2020;26:477-86.

33 Cramm JM, Finkenflügel HJM, Møller V, et al. TB treatment initiation and adherence in a South African community influenced more by perceptions than by knowledge of tuberculosis. BMC Public Health 2010;10:72.

34 Datiko DG, Jerene D, Suarez P. Stigma matters in ending tuberculosis: nationwide survey of stigma in Ethiopia. BMC Public Health 2020;20:190.

35 Somma D, Thomas BE, Karim F. Gender and socio-cultural determinants of TB-related stigma in Bangladesh, India, Malawi and Colombia. Int J Tuberc Lung Dis 2008;12:856-66.

36 Mushtaq MU, Shahid U, Abdullah HM, et al. Urban-rural inequities in knowledge, attitudes and practices regarding tuberculosis in two districts of Pakistan's Punjab province. Int J Equity Health 2011;10:8.

37 Kane JC, Elafros MA, Murray SM, et al. A scoping review of healthrelated stigma outcomes for high-burden diseases in low- and middle-income countries. BMC Med 2019;17:17.

38 Courtwright A, Turner AN. Tuberculosis and stigmatization: pathways and interventions. Public Health Rep 2010;125:34-42.

39 Chimbatata NBW, Zhou C-M, Chimbatata CM, et al. Post-2015, why delay to seek healthcare? perceptions and field experiences from TB healthcare providers in northern Malawi: a qualitative study. Infect Dis Poverty 2017;6:60. 